\title{
Mapping functional groups can provide insight into ecosystem functioning and potential resilience of intertidal sandflats
}

\author{
Barry L. Greenfield ${ }^{1}$, Casper Kraan ${ }^{1,2, *}$, Conrad A. Pilditch ${ }^{3}$, Simon F. Thrush ${ }^{4}$ \\ ${ }^{1}$ National Institute of Water and Atmospheric Research, PO Box 11-115, Hamilton 3216, New Zealand \\ ${ }^{2}$ Biometry and Environmental System Analysis, University of Freiburg, Tennenbacher Str. 4, 79106 Freiburg, Germany \\ ${ }^{3}$ School of Science, University of Waikato, Private Bag 3105, Hamilton 3240, New Zealand \\ ${ }^{4}$ Institute of Marine Science, University of Auckland, Private Bag 92019, Auckland 1142, New Zealand
}

ABSTRACT: The ability of species to maintain ecosystem functions under environmental stress depends on their vulnerability, adaptability and potential for dispersal and re-establishment. Species that share traits can perform similar functions, thus offering functional redundancy, and therefore potentially confer resilience in ecosystem function. In this regard, both species abundance and occurrence across a landscape are likely to affect the importance of redundancy. To investigate spatial patterns in functional redundancy, we assessed the degree to which specific functional traits linked to ecosystem function are shared, along with patterns of abundance and distribution, in a macrobenthic community (115 taxa; 23682 individuals) sampled in 400 plots from a large intertidal area $\left(300000 \mathrm{~m}^{2}\right)$. We defined 26 functional groups; $85 \%$ of these contained more than 1 species and $50 \%$ more than 3 species. Most functional group (22 of 26) distributions were non-random (as identified by Moran's $I$ ) and fell into 1 of 3 spatial patterns - gradients $(n=8$ function groups), and large ( $\mathrm{n}=2)$ and small patches $(\mathrm{n}=12)$ - that separate the functional attributes of the macrobenthic community. Only 2 functional groups exhibited low species richness and low abundance, but their widespread occurrence could provide resilience to small-scale disturbances. This spatial consideration of functional group distribution stresses the notion that resilience is likely to be scale-dependent rather than a commodity on offer across a whole system. Our findings emphasise the importance not only of within-functional group species richness but also of abundance and occurrence as a framework to investigate functional diversity and resilience of benthic seafloor communities.

${ }^{*}$ Corresponding author: casper.kraan@gmail.com

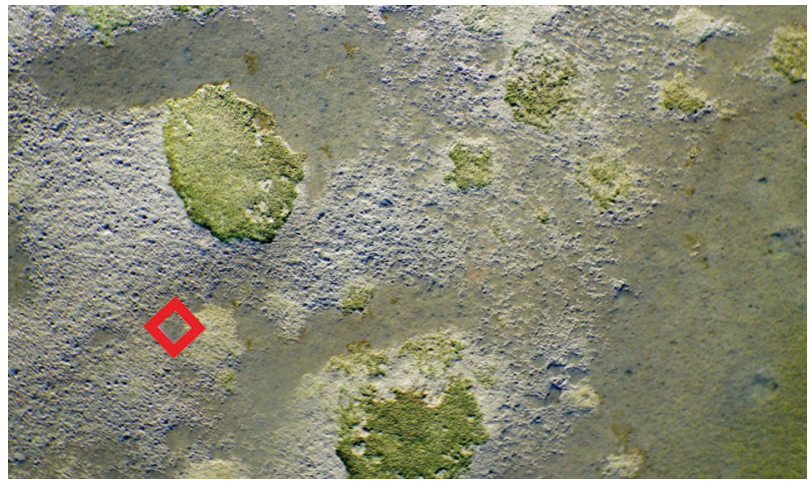

A portion of the sandflat (Kaipara Harbour, New Zealand) sampled to assess the spatial distribution of functional attributes in the macrobenthic community. The quadrat is $1 \mathrm{~m}^{2}$.

Photograph: Roman Zajac

KEY WORDS: Biodiversity - Ecosystem function · Functional redundancy $\cdot$ Functional traits $\cdot$ Intertidal · New Zealand · Scale-dependence · Spatial autocorrelation $\cdot$ Spatial variation

\section{INTRODUCTION}

Biodiversity encompasses many scales of variation in biological organisation and is critical for ecosystem functioning and productivity (Naeem et al. 1994, Tilman et al. 1996, Bengtsson 1998). Biodiversity enables efficient use of ecosystem resources due to a diversity of functions, performed by a range of species

() The authors 2016. Open Access under Creative Commons by Attribution Licence. Use, distribution and reproduction are unrestricted. Authors and original publication must be credited. 
occupying different niches, engaged in utilising and recycling resources (Tilman 1999). Therefore, conserving biodiversity is fundamental to maintaining the integrity of ecosystem functioning (e.g. Strong et al. 2015). Yet, despite conservation efforts, biodiversity is continuing to decline across a wide range of ecosystems (Bengtsson et al. 1997), due to habitat destruction, overexploitation, climate change, or species invasions (Mouillot et al. 2013). Thus, there is a pressing need to understand how biological features of ecological communities affect their response to stressors and which domains of scale should be studied to robustly describe the consequences of impacts on ecosystem function.

Research on the relationship between biodiversity and ecosystem functioning has taken 2 tracks. One is largely centred on the roles that single species play in regulating ecosystem processes (Wardle et al. 2000), whereas the other focusses on differences in species richness and evenness to explain changes in functional performance of communities (Hewitt et al. 2010). These aspects need to be reconciled because such richness- and evenness-based approaches assume that all species are potentially equal with respect to function, when in reality species can hold very different roles in contributing to ecosystem function (Posey 1987, Walker 1992, Bengtsson 1998). A focus on the functional role of only single species ignores potential complementarity and redundancy (Walker 1992). Where biological traits are shared by multiple species, functional redundancy can provide for continued function when individual species are lost due to their susceptibility to a specific stressor.

In this context, an additional major challenge of understanding ecosystem functioning lies in integrating spatial heterogeneity in the analysis of specific functional group abundances and traits (Thrush 1991, Legendre \& Legendre 2013, Violle et al. 2014). The abundance and occurrence of individual species within a functional group varies within and across habitats (Walker et al. 1999, Wellnitz \& Poff 2001, Rosenfeld 2002). Thus, redundancy within functional groups is likely to be affected by spatial heterogeneity in community composition (Naeem et al. 2012, Tscharntke et al. 2012). Therefore, descriptions of redundancy in trait representation alone are likely to be insufficient to provide realistic assessments of functional resilience. Conceptually, spatial variation in functional performance and connectivity between patches should influence resilience to stressors (Tscharntke et al. 2012).

Although species traits are commonly used as surrogates for ecosystem processes or functions, caveats on their use exist. Firstly, trait-function relationships are often not supported by mechanistic experiments (Snelgrove et al. 2014). Secondly, although species may appear to perform the same function (i.e. be redundant), their functional roles may vary across environments (Walker 1992, Wellnitz \& Poff 2001). For example, depending on sediment characteristics, the bivalve Macoma balthica can alternate between deposit- or suspension-feeding (Ólafsson 1986), and the crab Austrohelice crassa shifts from burrow builder to bulldozer across a mud-sand gradient (Needham et al. 2010), promoting different roles and functional associations in soft-sediment communities. However, underpinning trait-function relationships by mechanistic experiments across all possible traits and potential habitat dimensions is a major task. Therefore, traits are currently the best surrogates for function. Furthermore, summarising functional traits across all data has been pursued using single-trait (as in this study) or multi-trait indices. Although statistically advanced, the latter tend to obscure functional diversity patterns in complex landscapes, as they ignore community assembly processes (Spasojevic \& Suding 2012, Butterfield \& Suding 2013).

Marine benthic communities provide a unique opportunity to test ideas regarding the spatial architecture of functional diversity due to their high diversity, multiple trophic levels, ease of sampling, and the existence of large environmental gradients and a number of different habitats within relatively small areas (e.g. Snelgrove et al. 2014). In addition, functional traits have proved useful in marine systems to test relationships between functional diversity and ecosystem function (e.g. Törnroos \& Bonsdorff 2012, Rodil et al. 2013). To describe the spatial variation of a sandflat functional community, we sampled 115 taxa (referred to as 'species' throughout; 23682 individuals) and assigned each species to a functional group (Walker 1992, Törnroos \& Bonsdorff 2012). By examining the potential for the sharing of biological traits by species with different patterns of abundance and occurrence, we determined the degree of redundancy within functional groups (Gray et al. 2006, McGill et al. 2007, Gray \& Elliott 2009). Furthermore, spatial structure in functional group distributions was quantified by measures of spatial autocorrelation, i.e. the co-variation of group distributions with geographic space (e.g. Legendre \& Legendre 2013), which to date has received little attention. This approach not only acknowledges autocorrelation in analyses of the statistical validity on patterns, it also enhances ecological interpretation of complex data (Thrush 1991, Kraan et al. 2010, 2013). Additionally, we 
explored the importance of environmental variables for explaining the spatial variation in functional groups. Hence, we took the first steps to inform biodiversity-ecosystem functioning relationships by untangling the roles of spatial heterogeneity and functional group richness and abundance. Our analyses emphasise the role for spatial variation in functional diversity and redundancy in defining benthic community resilience.

\section{MATERIALS AND METHODS}

\section{Data collection}

$$
\text { Biological data }
$$

Samples were collected during April 2012 at 400 predetermined plots in an extensive intertidal sandflat in Kaipara Harbour, New Zealand. We used a spatially structured sampling design encompassing $300000 \mathrm{~m}^{2}$ that enabled us to sample a wide range of scales between $30 \mathrm{~cm}$ and $1 \mathrm{~km}$, balancing thenumber of plots for different distance classes and sampling effort (Kraan et al. 2015). Sampling covered an offshore gradient in the intertidal area from the high- to the low-water mark to ensure all environmental variation was included. Plots were located using handheld GPS (Garmin 78sc) and a $100 \mathrm{~m}$ tape measure. In each plot, a macrofaunal core (13 $\mathrm{cm}$ diameter, $20 \mathrm{~cm}$ deep) was collected and sieved (500 $\mu \mathrm{m}$ mesh), and the residue stored in $70 \%$ isopropyl alcohol (diluted with seawater). In the laboratory, samples were stained with $2 \%$ Rose Bengal, sorted and identified to the highest practical taxonomic resolution (mostly species level).

\section{Environmental data}

At each plot, $0.25 \mathrm{~m}^{2}$ of the sediment surface was photographed prior to any sampling disturbances to determine percentage coverage of the seagrass Zostera muelleri, shell hash (broken shell fragments) and bare sand. Coverage was estimated using 75 random points superimposed on the plot photos (see Kohler \& Gill 2006). Within the quadrat, 3 sediment cores $(2 \mathrm{~cm}$ dia- meter, $2 \mathrm{~cm}$ deep) were amalgamated to measure sediment particle size, organic content and chlorophyll a (chl a) concentration. Sediment samples remained in the dark and on ice until arrival at the laboratory, where they were freeze-dried prior to processing. Sediment particle size (median grain size in $\mu \mathrm{m}$ and percentage fractions - silt: $<63 \mu \mathrm{m}_{i}$ very fine:

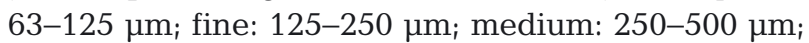
coarse: $>500 \mu \mathrm{m})$, organic content and chl $a\left(\mathrm{mg} \mathrm{g}^{-1}\right)$ were analysed following Needham et al. (2011) and Jones et al. (2011).

Traits data

All 115 species were assigned to at least 1 of the traits for each of 6 functional attributes reflecting life history, morphology and behavioural aspects that are linked to sediment biochemistry and stability (Table 1; Rodil et al. 2013, Snelgrove et al. 2014). We focussed on these ecosystem functions, as the effects of macrobenthic fauna on their performance have been shown (e.g. Jones et al. 2011, Thrush et al. 2014, Lohrer et al. 2015). Functional groups were derived from a trait-based index (Rodil et al. 2013), taxonomic information such as the Marine Life Information Network (MarLIN; www.marlin.ac.uk) and

Table 1. Functional attributes, traits and codes for macrobenthic fauna

\begin{tabular}{|c|c|c|}
\hline $\begin{array}{l}\text { Functional } \\
\text { attribute }\end{array}$ & Functional trait & Code \\
\hline Body hardness & $\begin{array}{l}\text { Calcified (fully calcified shell) } \\
\text { Soft-bodied } \\
\text { Rigid (chitinous exoskeleton or endoskeleton) }\end{array}$ & $\begin{array}{l}\text { B } \\
\text { C } \\
\text { D }\end{array}$ \\
\hline Feeding behaviour & $\begin{array}{l}\text { Suspension-feeder } \\
\text { Deposit-feeder } \\
\text { Predator/scavenger } \\
\text { Grazer }\end{array}$ & $\begin{array}{l}E \\
F \\
G \\
H\end{array}$ \\
\hline Living position & $\begin{array}{l}\text { Attached } \\
\text { Above surface } \\
\text { Top } 2 \mathrm{~cm} \\
\text { Below surface (movement between layers) } \\
\text { Deep }\end{array}$ & $\begin{array}{l}\mathrm{I} \\
\mathrm{J} \\
\mathrm{K} \\
\mathrm{L} \\
\mathrm{M}\end{array}$ \\
\hline Movement ability & $\begin{array}{l}\text { Freely mobile on or in sediment } \\
\text { Limited movement, usually in sediment } \\
\text { Sedentary/movement in a fixed tube }\end{array}$ & $\begin{array}{l}\mathrm{N} \\
\mathrm{O} \\
\mathrm{P}\end{array}$ \\
\hline $\begin{array}{l}\text { Living structure } \\
\text { created }\end{array}$ & $\begin{array}{l}\text { Tube } \\
\text { Permanent burrow } \\
\text { Large burrow (larger crustaceans) } \\
\text { None }\end{array}$ & $\begin{array}{l}\mathrm{Q} \\
\mathrm{R} \\
\mathrm{S} \\
\mathrm{T}\end{array}$ \\
\hline $\begin{array}{l}\text { Body size (based on } \\
\text { adult size sourced } \\
\text { from literature) }\end{array}$ & $\begin{array}{l}\text { Small }(<5 \mathrm{~mm}) \\
\text { Medium }(5-20 \mathrm{~mm}) \\
\text { Large }(>20 \mathrm{~mm})\end{array}$ & $\begin{array}{l}\mathrm{U} \\
\mathrm{V} \\
\mathrm{W}\end{array}$ \\
\hline
\end{tabular}


the World Register of Marine Species (WoRMS; www.marinespecies.org), relevant literature (e.g. Hewitt et al. 2008) and results from extensive experimental field studies (e.g. Thrush et al. 2014 and references therein, Lohrer et al. 2015). We used fuzzy coding (Chevene et al. 1994) for 8 species, which we could not clearly assign to a single functional group. This initially resulted in 77 functional groups representing different trait combinations. We aggregated functional groups whose impacts on sediment biogeochemistry and stability were shared. For exam- ple, we did not distinguish between predatory and scavenging gastropods because feeding mode was unlikely to affect the functions of interest. On average, $75 \%$ of the individuals in a functional group harboured the dominant/reported traits. Size was included for only those taxa for which it has been recognised to be important to ecosystem functioning, such as large bioturbating bivalves (Norkko et al. 2013). This approach resulted in 26 functional groups (Table 2, Table S1 at www.int-res.com/articles/suppl/ m548p001_supp.pdf), consisting of 1 to 13 species.

Table 2. Functional group number (n species), trait code (see Table 1), description of dominant traits and example species (see Table S1 at www.int-res.com/articles/suppl/m548p001_supp.pdf for a full species list, including their occurrence and abundance)

\begin{tabular}{|c|c|c|c|}
\hline Group (n) & Trait code & Description & Example \\
\hline $1(3)$ & BEIPTU & Calcified, suspension-feeding, attached & Austrominius modestus \\
\hline $2(2)$ & BEKNTW & Calcified, suspension-feeding, top $2 \mathrm{~cm}$, freely mobile & Austrovenus stutchburyi \\
\hline $3(4)$ & BEKOTU & Calcified, suspension-feeding, top $2 \mathrm{~cm}$, limited mobility & Soletellina siliquens \\
\hline $4(1)$ & BEKPTV & Calcified, suspension-feeding, top $2 \mathrm{~cm}$, sedentary & Musculista senhousia \\
\hline $5(11)$ & BGJNTV & $\begin{array}{l}\text { Calcified, deposit/predator/scavenger/grazer, above surface, } \\
\text { freely mobile }\end{array}$ & Zeacumantus lutulentus \\
\hline $6(5)$ & BFKOTU & Calcified, deposit-feeding, top $2 \mathrm{~cm}$, limited mobility & Linucula hartvigiana \\
\hline $7(3)$ & BFKNTU & $\begin{array}{l}\text { Calcified, deposit-feeding, predator/scavenger, top } 2 \mathrm{~cm} \text {, } \\
\text { freely mobile }\end{array}$ & Pisinna zosterophila \\
\hline $8(2)$ & BFMOTW & $\begin{array}{l}\text { Calcified, deposit-feeding, deep, limited mobility, } \\
\text { no habitat structure, large }\end{array}$ & Macomona liliana \\
\hline $9(1)$ & CEIPTV & Soft-bodied, suspension-feeding, attached & Anthopleura aureoradiata \\
\hline $10(4)$ & CEKQPV & Soft-bodied, suspension-feeding, tube structure & Boccardia syrtis \\
\hline $11(1)$ & CFKNTW & Soft-bodied, deposit-feeding, top $2 \mathrm{~cm}$, freely mobile & Travisia olens \\
\hline $12(4)$ & CFLNTV & Soft-bodied, deposit-feeding, below surface, freely mobile & Orbinia papillosa \\
\hline $13(13)$ & CFLOTU & Soft-bodied, deposit-feeding, below surface, limited mobility & Heteromastus filiformis \\
\hline $14(3)$ & CFMORU & Soft-bodied, deposit-feeding, deep & Barantolla lepte \\
\hline $15(6)$ & CFLPQU & Soft-bodied, below surface, tube structure & Owenia petersenae \\
\hline $16(3)$ & CGKNTU & Soft-bodied, predator/scavenger, top $2 \mathrm{~cm}$, freely mobile & Dorvillea sp. \\
\hline $17(5)$ & CGKOTV & Soft-bodied, predator/scavenger, top $2 \mathrm{~cm}$, limited mobility & Oligochaeta \\
\hline $18(13)$ & CGLNTU & $\begin{array}{l}\text { Soft-bodied, predator/scavenger, below surface, deep, } \\
\text { freely mobile, no habitat structure }\end{array}$ & Aglaophamus macroura \\
\hline $19(3)$ & CGLOTU & $\begin{array}{l}\text { Soft-bodied, predator/scavenger, below surface, } \\
\text { limited mobility }\end{array}$ & Hesionidae spp. \\
\hline $20(3)$ & CFLPQV & $\begin{array}{l}\text { Soft-bodied, above surface, top } 2 \mathrm{~cm} \text {, below surface, } \\
\text { deep, sedentary, tube structure }\end{array}$ & Phoronis sp. \\
\hline $21(5)$ & DEKNRV & Rigid, suspension-feeding, top $2 \mathrm{~cm}$ & Paracorophium spp. \\
\hline $22(11)$ & DGKNTU & $\begin{array}{l}\text { Rigid, deposit-feeding, predator/scavenger, top } 2 \mathrm{~cm} \text {, } \\
\text { freely mobile, no habitat structure }\end{array}$ & Waitangi brevirostris \\
\hline $23(6)$ & DGJNTV & Rigid, above surface, freely mobile & Colurostylis lemurum \\
\hline $24(2)$ & DFJNTW & Rigid, above surface, freely mobile, large & Ophiuroidea sp. \\
\hline $25(1)$ & DGIOTU & Rigid, predator/scavenger, attached & Pinnotheres novaezelandiae \\
\hline $26(8)$ & DGJNSW & $\begin{array}{l}\text { Rigid, predator/scavenger, below surface, freely mobile, } \\
\text { large burrow former }\end{array}$ & Hemiplax hirtipes \\
\hline
\end{tabular}




\section{Data analysis}

To verify that we had collected sufficient samples to capture benthic and functional diversity, species and functional group accumulation curves were generated using PRIMER (Clarke \& Warwick 2001, Anderson et al. 2008). We based our assessment on the Ugland, Gray and Ellingsen distribution (Ugland et al. 2003), as it recognises that heterogeneity in species richness can occur within subareas, and that this may have important consequences for estimating species richness (see Mao \& Colwell 2005, Thrush et al. 2006).

Moran's I coefficient (see Kraan et al. 2009, 2010) was used to quantify the degree of correlation between samples with increasing distance (Dormann et al. 2007, Legendre \& Legendre 2013), using the program Spatial Analysis in Macroecology (SAM; Rangel et al. 2010). Values range from +1 (strong spatial clumping), 0 (random distribution), to -1 (extreme evenly dispersed distribution). Plots of Moran's $I$ values against distance, so-called correlograms, offer information on patterns in the spatial distribution of variables (Kraan et al. 2010, Legendre \& Legendre 2013). To ensure comparable power to detect differences in functional group abundances, defined as the number of individuals within a functional group, similar numbers of sampling points within each distance interval were used in all distance classes (ranging from 9812 to 10080 pairs). Significance of Moran's I values were determined using 999 permutations at a significance level of 0.05 , followed by a sequential Bonferroni correction to account for multiple testing (Legendre \& Legendre 2013).

To assess how much of such spatial variation could be attributed to environmental factors, we used canonical correspondence analysis (CCA) to assess the relationship between the 26 functional groups and sedimentary variables using CANOCO v.4.5 (ter Braak \& Smilauer 2002). Raw abundances with down weighting of rare species - i.e. giving such species a lower weight than the more common species based on their frequency of occurrence - were used, as this improved explained variation by the first 2 ordination axes and provided a better spread between them (ter Braak \& Smilauer 2002).

\section{RESULTS}

The accumulation curves (see Fig. S1 at www.intres.com/articles/suppl/m548p001_supp.pdf) indicated that we were able to characterise the community and functional groups after collecting approximately 30 samples. The 4 most common functional groups were small deposit-feeding polychaetes (Group 13; $27 \%$ abundance), large suspension-feeding and mobile bivalves (Group 2; $11 \%$ abundance), tube-forming polychaetes (Group 10; $9 \%$ abundance) and deepliving deposit-feeding bivalves (Group 8; 9\% abundance). A total of 17 functional groups had $<5 \%$ total cumulative abundance and 10 had cumulative abundances $<1 \%$ (see Table 1).

Functional redundancy conferred by withinfunctional group species richness was common with $85 \%$ of the functional groups containing $>1$ species, $63 \%$ with 3 species and $50 \%$ containing $>3$ species (Tables 2 \& S1). The 4 functional groups with the highest redundancy were small deposit-feeding polychaetes (Group 13; 13 species), predator/scavenger polychaetes (Group 18; 13 species), isopods/ amphipods occurring in the top $2 \mathrm{~cm}$ of the sediment (Group 22; 11 species) and surface-dwelling mobile gastropods (Group 5; 11 species). Functional groups encompassing large suspension-feeding and mobile bivalves, deep-living deposit-feeding bivalves, or large above-surface mobile Asterozoa, were composed of only 2 species (Tables $2 \&$ S1). The mean number of species per functional group was 5. A total of 4 functional groups (i.e. 9, 11, 4 and 25) were represented by only 1 species each, i.e. Anthopleura aureoradiata, Travisia olens, Musculista senhousia and Pinnotheres novaezelandiae, respectively.

The number of times a functional group was found in the 400 plots, i.e. occurrence, was classified as high $(>50 \%)$, medium $(10-50 \%)$ or low $(<10 \%)$. Groups characterised by deposit- and suspensionfeeding bivalves, or tube-forming polychaetes (e.g. Group 15), had high occurrence, indicating these groups are widely distributed. For example, Group 13 occurred in $93 \%$ of the plots. Functional groups associated with deep-living or being attached to other species/substrates were typically associated with low occurrences (e.g. Group 9), as they are very patchily distributed. Functional groups that do not lead to direct changes of the sediment biochemistry and stability, such as soft-bodied scavengers (e.g. Group 17), scored a medium occurrence (see Table S1 for abundance information).

Functional groups showed substantial variation in their spatial patterns. Random distributions were shown by only 4 functional groups $(7,16,24,25)$ (Fig. 1 and see Fig. S2 in the Supplement for all functional groups). Most functional groups fell into 1 of the following 3 types of pattern: (1) gradients (shown by 8 functional groups: 1, 2, 4, 10, 12, 15, 17, 20), where functional group abundance becomes increas- 
$\mathbf{a}$
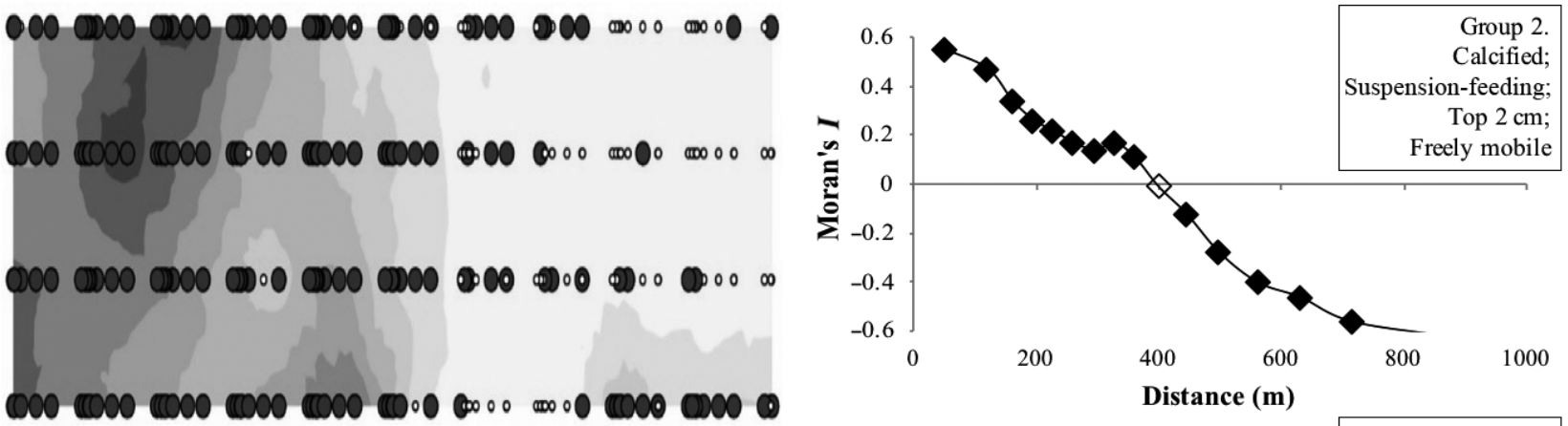

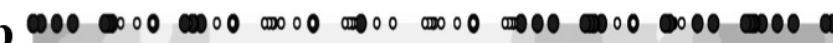
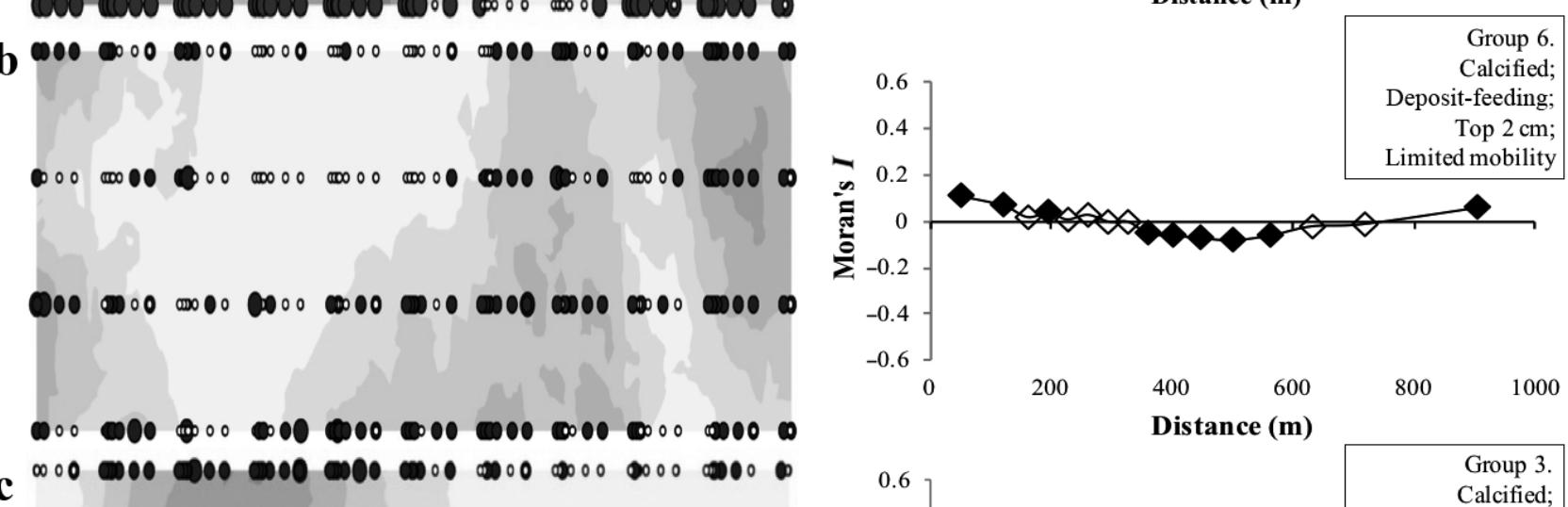

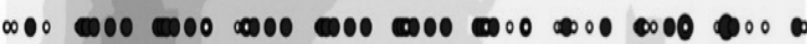

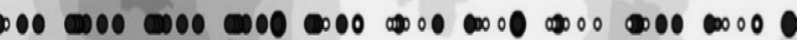

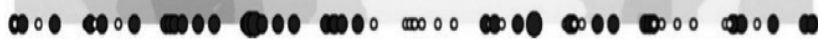

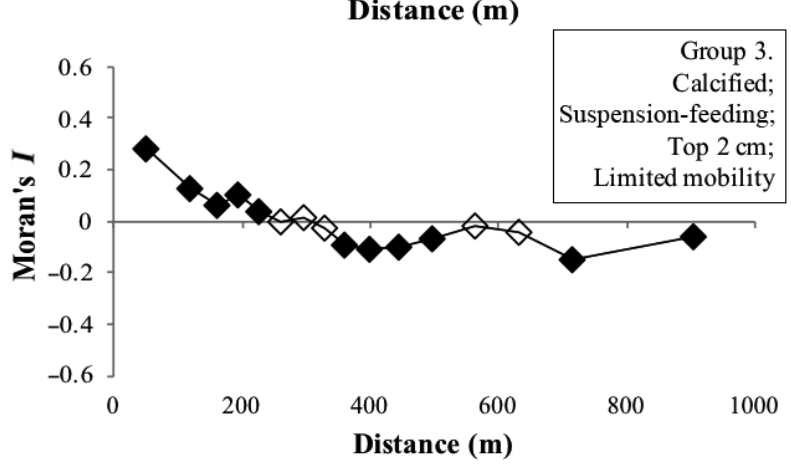

Fig. 1. Left: spatial distribution of functional groups based on interpolated (log-transformed) abundances (filled contours; darker shading denotes higher abundances; range 0 to 2.1) and functional group richness (scaled points; larger points indicate higher richness; the largest number of co-occurring species within a functional group is 6 species [see Fig. S2 in the Supplement at www.int-res.com/articles/suppl/m548p001_supp.pdf]). Right: correlograms, based on functional group abundance (see left panels), illustrate (a) a gradient, (b) a large patch and (c) multiple patches. Filled symbols denote significant Moran's I values.

Note that (a) is truncated at -0.6

ingly different as the distance between samples increases, shown by points farther apart having very different Moran's I coefficients; (2) large patches (shown by 2 functional groups: 6, 13), represented by significant positive autocorrelations at the shortest and longest distances, with negative correlations in the intermediate distance classes; and (3) multiple patches (shown by 12 functional groups: 3, 5, 8, 9, 11 , $14,18,19,21,22,23,26)$, where an oscillation of significant positive autocorrelation is followed by negative autocorrelation. The interpretation of correlograms exhibiting large patches is difficult, as such structures are typical of either spatial patterns dominated by one large patch or a saddle-shaped pattern (e.g. Legendre \& Fortin 1989). Maps (see left sides of Figs. 1 \& S2) confirmed these patterns to be based on large patch structures.

Explained variation by the first CCA axis was $25.7 \%(p=0.002)$ and by the second CCA axis was $11.7 \%(p=0.002)$, while the total amount explained by sedimentary variables collectively was a modest $28 \%$ (Fig. 2). For example, Group 2 (large mobile suspension-feeding bivalves) was weakly positively correlated with medium/coarse sand and weakly negatively correlated with fine particles, whereas Groups 10, 15 and 20 (variations of tube-forming polychaete) were weakly negatively correlated to the latter environmental characteristics. One of the most 


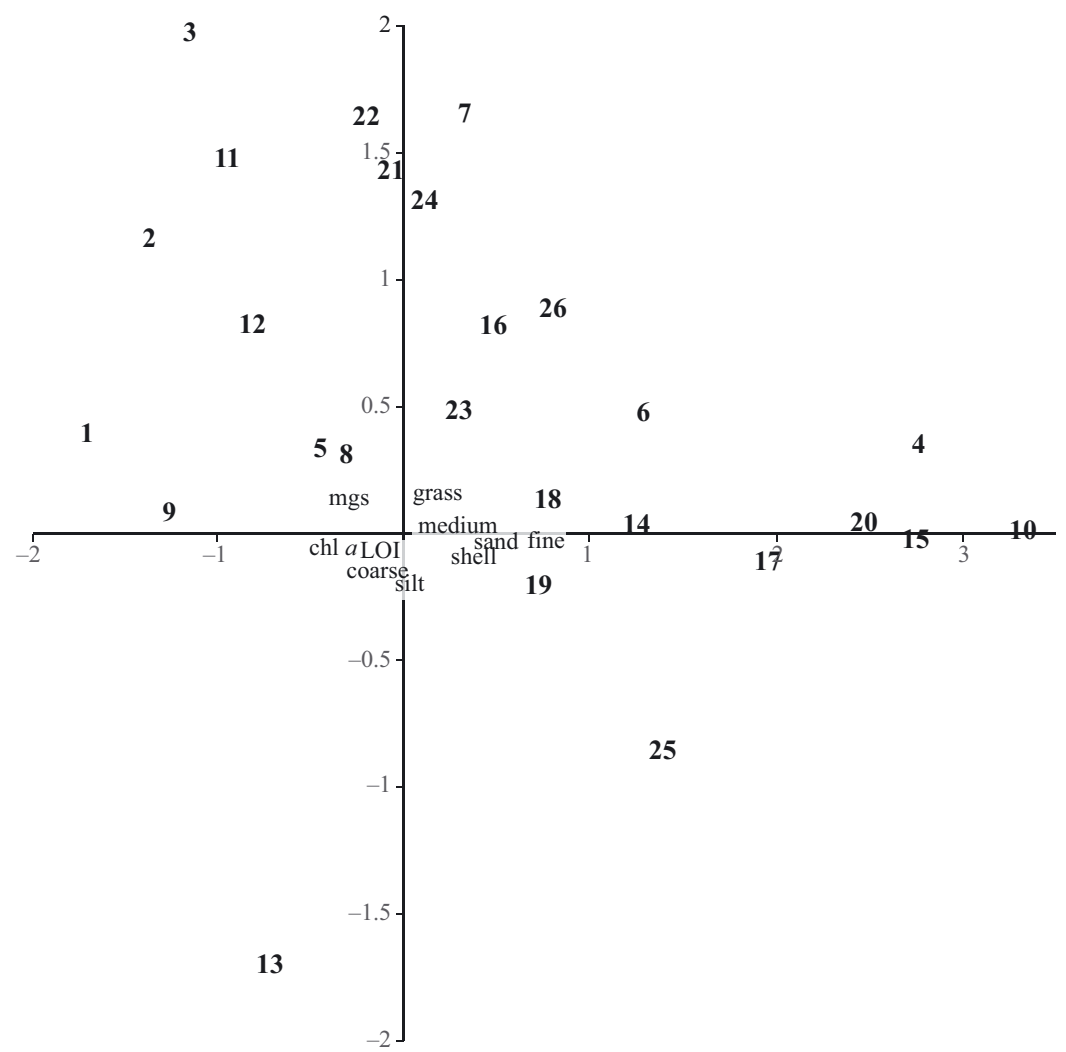

Fig. 2. Canonical correspondence analysis between the 26 functional groups (indicated by numbers, see Table 2 ) and sedimentary variables: median grain size (mgs), silt, fine, medium and coarse sand, chl a content (chl a), organic content (LOI), and surface coverage of bare sand (sand), shell hash (shell) and seagrass (grass)

species-rich functional groups, Group 18 (mobile predator/scavenger polychaetes), was negatively correlated with chl $a$ and organic content, and preferred finer sediments. The distribution of Groups 5 (surface-dwelling gastropods), 7 (top $2 \mathrm{~cm}$ mobile deposit-feeding gastropods), 16 (top $2 \mathrm{~cm}$ mobile predator polychaetes), 22 (isopoda/amphipoda top $2 \mathrm{~cm}$ ), 24 (large above-surface mobile Asterozoa) and 26 (large burrow-forming crustaceans) appeared to be related to seagrass cover and silt concentration.

\section{DISCUSSION}

Addressing spatial heterogeneity in diversity is critical, as increased anthropogenic stress often leads to habitat homogenisation, thereby threatening biodiversity (Loreau et al. 2001, Naeem 2002). Our empirical study defines spatial heterogeneity of functional diversity and redundancy as a proxy for resilience of biodiversity-ecosystem function relationships across $300000 \mathrm{~m}^{2}$ of superficially homogeneous sandflat. As such, it provides an illustration of functional diversity, based on abundance, occurrence and spatial structure of functional group distributions. There were spatial gradients and clear boundaries of abundance and occurrence separating the functional attributes of the benthic community.

Redundancy is an important element of resilience, whereby a greater number of species performing the same function act to reinforce that function against the negative impacts of stressors (Cardinale et al. 2012, Naeem et al. 2012). With $85 \%$ of groups consisting of 2 or more species, and $50 \%$ containing 4 or more species, most functional groups in this study showed a degree of redundancy. Additional elements of resilience, i.e. abundance and occurrence, are often ignored. Yet, functional groups that have a high abundance coupled with low occurrence may be, for example, more vulnerable to small-scale or point-source stressors that can devastate the population (de Juan et al. 2007, Rodil et al. 2011). Similarly, functional groups with low abundances and high occurrence may be more resilient to small-scale stressors because they can readily re-colonise following a disturbance, e.g. after a predation (Thrush et al. 1994) or localised sedimentation event (Norkko et al. 2013). Although they are not locally abundant per se, they are likely to have a high degree of redundancy provided by their broad-scale occupancy. These additional elements of resilience should affect how we interpret functional group redundancy based solely on species richness and the consequences of localised disturbances/stressors in a heterogeneous landscape on ecosystem function.

On New Zealand sandflats, 2 functional groups (Group 2: large mobile suspension-feeding bivalves; Group 8: large and deep-living deposit-feeding bivalves) are of critical importance to community architecture and sediment biochemistry (Thrush et al. 2012, 2014, Pratt et al. 2015). Each of these groups is dominated by a single abundant and widely occurring species, Austrovenus stutchburyi $(\mathrm{n}=929$, occurring in $55 \%$ of the samples) in Group 2 and Macomona liliana ( $\mathrm{n}=1952$, occurring in $95 \%$ of the samples) in Group 8. While low redundancy in these 
functional groups ( $\mathrm{n}=2$ species) indicates vulnerability (e.g. Micheli \& Halpern 2005), this may not necessarily be offset by high abundance if occupancy is low (i.e. all individuals concentrated in one place).

The spatial extent of stressors is a very important aspect of predicting changes in resilience (Thrush et al. 2000, 2005, Hewitt et al. 2010). Some stressors, such as storms or desiccation events, are likely to influence the whole sandflat ecosystem (Gray \& Elliott 2009 and references therein). Others, such as predator impacts (e.g. eagle rays or shorebirds), are local. It is therefore necessary to determine the spatial distribution and environmental range of functional groups in order to assess their resilience to different types of stress or disturbance (Legendre \& Legendre 2013). The spatial patterning of functional groups was quite diverse across the site. Species-rich functional groups characterised by small depositfeeding polychaetes, amphipods and isopods (e.g. Group 21) were distributed throughout the site in various abundances. Alternatively, tube-forming polychaetes (e.g. Group 10) showed aggregations and marked boundaries to their distribution, which suggests this functional group may be vulnerable to small-scale stressors. Differences in biological (physical and behavioural) use of habitat are likely to be influencing the opposing spatial structure of functional groups. Large suspension-feeding and mobile bivalves (e.g. A. stutchburyi or Paphies australis) destabilise sediments (Posey 1987). In contrast, tubeworms (e.g. Boccardia syrtis) stabilise sediments (Fager 1964, Posey 1987) and are therefore directly conflicting with the former functional group. Spatial distribution of large predatory polychaetes, such as Ceratonereis sp. or Glycinde spp., may also cause heterogeneity in spatial structure.

Functional groups may have apparent resilience due to their abundance and occupancy characteristics, but they might in fact still be highly vulnerable owing to their low tolerance to environmental stress (Walker 1992, Walker et al. 1999). Environmental variables are typically a major influence on spatial distribution and diversity (Thrush et al. 2005, Kraan et al. 2010, 2015). Indeed, CCA indicated that measured environmental parameters were moderately related (total explained variance $28 \%$ ) to the distribution of functional groups in the ordination space. This therefore suggests that, in addition to the measured environmental variables, biological interactions between functional groups are likely to be driving the spatial structure of functionality at the site (see Legendre \& Legendre 2013), or that the environmental variables important for structuring benthic com- munities at this scale have not been measured (Kraan et al. 2015).

Our analysis of 115 species across $300000 \mathrm{~m}^{2}$ of sandflat offers a demonstration of how redundancy needs to be linked to patterns of trait richness, abundance, occupancy and spatial pattern in order to gain insight into functional redundancy as a proxy for resilience. The community and traits approach demonstrated that variations in the presence of particular functions are common, even across a single intertidal sandflat. In addition, there were marked and contrasting differences in their spatial distributions.

Acknowledgements. This work was supported by the Marsden Fund of the Royal Society of New Zealand (NIW-1102) to S.F.T. and C.K., and a Marie-Curie Fellowship (FP7-PEOPLE-2011-IOF) to C.K. We thank Sylvia de Juan, Andres Ospina, Katie Cartner, Kelly Carter, Sarah Hailes, Hazel Needham, Clarisse Niemand, Rachel Harris and Rebecca Gladstone-Gallagher for their help during field and laboratory work. Comments and input by Daniel C. Laughlin, Anna Villnäs and Judi Hewitt, and 3 anonymous reviewers, greatly improved clarity and focus of the paper.

\section{LITERATURE CITED}

Anderson M, Gorley R, Clarke K (2008) PERMANOVA+ for Primer: guide to software and statistical methods. Primer-E, Plymouth

Bengtsson J (1998) Which species? What kind of diversity? Which ecosystem function? Some problems in studies of relations between biodiversity and ecosystem function. Appl Soil Ecol 10:191-199

Bengtsson J, Jones H, Setälä H (1997) The value of biodiversity. Trends Ecol Evol 12:334-336

Butterfield BJ, Suding KN (2013) Single-trait functional indices outperform multi-trait indices in linking environmental gradients and ecosystem services in a complex landscape. J Ecol 101:9-17

> Cardinale BJ, Duffy JE, Gonzalez A, Hooper DU and others (2012) Biodiversity loss and its impact on humanity. Nature 486:59-67

> Chevene F, Doleadec S, Chessel D (1994) A fuzzy coding approach for the analysis of long-term ecological data. Freshw Biol 31:295-309

Clarke K, Warwick R (2001) Changes in marine communities: an approach to statistical analysis and interpretation. Primer-E, Plymouth

de Juan S, Thrush SF, Demestre M (2007) Functional changes as indicators of trawling disturbance on a benthic community located in a fishing ground (NW Mediterranean Sea). Mar Ecol Prog Ser 334:117-129

> Dormann CF, McPherson JM, Araújo MB, Bivand R and others (2007) Methods to account for spatial autocorrelation in the analysis of species distributional data: a review. Ecography 30:609-628

Fager EW (1964) Marine sediments: effects of a tubebuilding polychaete. Science 143:356-358

Gray JS, Elliott M (2009) Ecology of marine sediments. Oxford University Press, Oxford 
Gray JS, Bjørgesæter A, Ugland KI (2006) On plotting species abundance distributions. J Anim Ecol 75:752-756

> Hewitt JE, Thrush SF, Dayton PD (2008) Habitat variation, species diversity and ecological functioning in a marine system. J Exp Mar Biol Ecol 366:116-122

Hewitt JE, Thrush SF, Lohrer AM, Townsend M (2010) A latent threat to biodiversity: consequences of small-scale heterogeneity loss. Biodiversity Conserv 19:1315-1323

> Jones HF, Pilditch CA, Bruesewitz DA, Lohrer AM (2011) Sedimentary environment influences the effect of an infaunal suspension feeding bivalve on estuarine ecosystem function. PLoS ONE 6:e27065

> Kohler KE, Gill SM (2006) Coral point count with Excel extensions (CPCe): a Visual Basic program for the determination of coral and substrate coverage using random point count methodology. Comput Geosci 32:1259-1269

Kraan C, van der Meer J, Dekinga A, Piersma T (2009) Patchiness of macrobenthic invertebrates in homogenized intertidal habitats: hidden spatial structure at a landscape scale. Mar Ecol Prog Ser 383:211-224

Kraan C, Aarts G, van der Meer J, Piersma T (2010) The role of environmental variables in structuring landscapescale species distributions in seafloor habitats. Ecology 91:1583-1590

Kraan C, Aarts G, Piersma T, Dormann CF (2013) Temporal variability of ecological niches: a study on intertidal benthic fauna. Oikos 122:754-760

> Kraan C, Dormann CF, Greenfield BL, Thrush SF (2015) Cross-scale variation in biodiversity-environment links illustrated by coastal sandflat communities. PLoS ONE 10:e0142411

> Legendre P, Fortin MJ (1989) Spatial patterns and ecological analysis. Vegetatio 80:107-138

Legendre P, Legendre L (2013) Numerical ecology. Elsevier, Amsterdam

- Lohrer AM, Thrush SF, Hewitt JE, Kraan C (2015) The upscaling of ecosystem functions in a heterogeneous world. Sci Rep 5:10349

Loreau M, Naeem S, Inchausti P, Bengtsson J and others (2001) Biodiversity and ecosystem functioning: current knowledge and future challenges. Science 294:804-808

Mao CX, Colwell RK (2005) Estimation of species richness: mixture models, the role of rare species, and inferential challenges. Ecology 86:1143-1153

McGill BJ, Etienne RS, Gray JS, Alonso D and others (2007) Species abundance distributions: moving beyond single prediction theories to integration within an ecological framework. Ecol Lett 10:995-1015

Micheli F, Halpern BS (2005) Low functional redundancy in coastal marine assemblages. Ecol Lett 8:391-400

Mouillot D, Bellwood DR, Baraloto C, Chave J and others (2013) Rare species support vulnerable functions in highdiversity ecosystems. PLoS Biol 11:e1001569

Naeem S (2002) Ecosystem consequences of biodiversity loss: the evolution of a paradigm. Ecology 83:1537-1552

> Naeem S, Thompson LJ, Lawler SP, Lawton JH, Woodfin RM (1994) Declining biodiversity can alter the performance of ecosystems. Nature 368:734-737

Naeem S, Duffy JE, Zavaleta E (2012) The functions of biological diversity in an age of extinction. Science 336: 1401-1406

Needham HR, Pilditch CA, Lohrer AM, Thrush SF (2010) Habitat dependence in the functional traits of Austrohelice crassa, a key bioturbating species. Mar Ecol Prog Ser 414:179-193
Needham HR, Pilditch CA, Lohrer AM, Thrush SF (2011) Context-specific bioturbation mediates changes to ecosystem functioning. Ecosystems 14:1096-1109

Norkko A, Villnäs A, Norkko J, Valanko S, Pilditch C (2013) Size matters: implications of the loss of large individuals for ecosystem function. Sci Rep 3:2646

Ólafsson EB (1986) Density dependence in suspension-feeding and deposit-feeding populations of the bivalve Macoma balthica - a field experiment. J Anim Ecol 55: 517-526

Posey MH (1987) Influence of relative mobilities on the composition of benthic communities. Mar Ecol Prog Ser 39: 99-104

Pratt DR, Pilditch CA, Lohrer AM, Thrush SF, Kraan C (2015) Spatial distributions of grazing activity and microphytobenthos reveal scale-dependent relationships across a sedimentary gradient. Estuaries Coasts 38: 722-734

Rangel TF, Diniz-Filho JAF, Bini LM (2010) SAM: a comprehensive application for spatial analysis in macroecology. Ecography 33:46-50

> Rodil IF, Lohrer AM, Chiaroni LD, Hewitt JE, Thrush SF (2011) Disturbance of sandflats by thin terrigenous sediment deposits: consequences for primary production and nutrient cycling. Ecol Appl 21:416-426

Rodil IF, Lohrer AM, Hewitt JE, Townsend M and others (2013) Tracking environmental stress gradients using three biotic integrity indices: advantage of a locallydeveloped traits-based approach. Ecol Indic 34:560-570

> Rosenfeld JS (2002) Functional redundancy in ecology and conservation. Oikos 98:156-162

Snelgrove PVR, Thrush SF, Wall DH, Norkko A (2014) Real world biodiversity-ecosystem functioning: a seafloor perspective. Trends Ecol Evol 29:398-405

Spasojevic MJ, Suding KN (2012) Inferring community assembly mechanisms from functional diversity patterns: the importance of multiple assembly processes. J Ecol 100:652-661

Strong JA, Andonegi E, Bizsel KC, Danovaro R and others (2015) Marine biodiversity and ecosystem function relationships: the potential for practical monitoring applications. Est Coast Shelf Sci 161:46-64

ter Braak CJ, Smilauer P (2002) CANOCO reference manual and CanoDraw for Windows user's guide: software for Canonical community ordination (version 4.5). Microcomputer Power, Ithaca

Thrush SF (1991) Spatial patterns in soft-bottom communities. Trends Ecol Evol 6:75-79

Thrush SF, Pridmore RD, Hewitt JE, Cummings VJ (1994) The importance of predators on a sandflat: interplay between seasonal changes in prey densities and predator effects. Mar Ecol Prog Ser 107:211-222

> Thrush SF, Hewitt JE, Cummings VJ, Green MO and others (2000) The generality of field experiments: interactions between local and broad-scale processes. Ecology 81: 399-415

Thrush SF, Hewitt JE, Herman PM, Ysebaert T (2005) Multiscale analysis of species-environment relationships. Mar Ecol Prog Ser 302:13-26

> Thrush SF, Gray JS, Hewitt JE, Ugland KI (2006) Predicting the effects of habitat homogenization on marine biodiversity. Ecol Appl 16:1636-1642

> Thrush SF, Hewitt JE, Lohrer AM (2012) Interaction networks in coastal soft-sediments highlight the potential for change in ecological resilience. Ecol Appl 22:1213-1223 
Thrush SF, Hewitt JE, Parkes S, Lohrer AM and others (2014) Experimenting with ecosystem interaction networks in search of threshold potentials in real world marine ecosystems. Ecology 95:1451-1457

Tilman D (1999) The ecological consequences of changes in biodiversity: a search for general principles. Ecology 80: 1455-1474

Tilman D, Wedin D, Knops J (1996) Productivity and sustainability influenced by biodiversity in grassland ecosystems. Nature 379:718-720

Törnroos A, Bonsdorff E (2012) Developing the multitrait concept for functional diversity: lessons from a system rich in functions but poor in species. Ecol Appl 22: 2221-2236

Tscharntke T, Tylianakis JM, Rand TA, Didham RK and others (2012) Landscape moderation of biodiversity patterns and processes - eight hypotheses. Biol Rev Camb Philos Soc 87:661-685

Editorial responsibility: Charles Peterson, Morehead City, North Carolina, USA
Ugland KI, Gray JS, Ellingsen KE (2003) The speciesaccumulation curve and estimation of species richness. J Anim Ecol 72:888-897

> Violle C, Reich PB, Pacala SW, Enquist BJ, Kattge J (2014) The emergence and promise of functional biogeography. Proc Natl Acad Sci USA 111:13690-13696

Walker BH (1992) Biodiversity and ecological redundancy. Conserv Biol 6:18-23

Walker B, Kinzig A, Langridge J (1999) Original articles: plant attribute diversity, resilience, and ecosystem function: the nature and significance of dominant and minor species. Ecosystems 2:95-113

Wardle DA, Huston MA, Grime JP, Berendse F and others (2000) Biodiversity and ecosystem function: an issue in ecology. Bull Ecol Soc Am 81:235-239

Wellnitz T, Poff NL (2001) Functional redundancy in heterogeneous environments: implications for conservation. Ecol Lett 4:177-179

Submitted: November 11, 2015; Accepted: March 7, 2016 Proofs received from author(s): April 1, 2016 